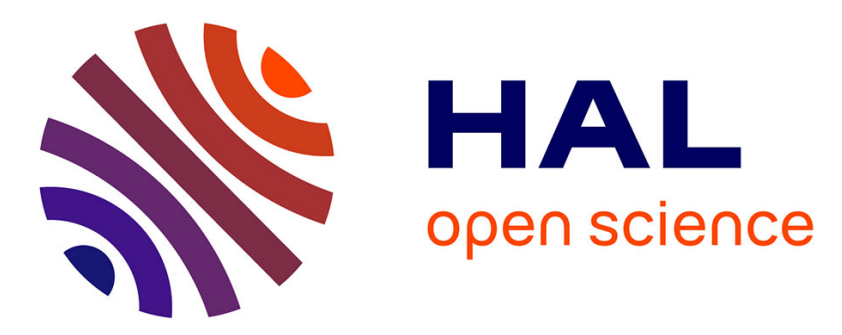

\title{
A Conformal Band-Notched Ultrawideband Antenna with Monopole-Like Radiation Characteristics
}

B. Mohamadzade, R.B.V.B. Simorangkir, R.M. Hashmi, Y. Chao-Oger, M. Zhadobov, R. Sauleau

\section{- To cite this version:}

B. Mohamadzade, R.B.V.B. Simorangkir, R.M. Hashmi, Y. Chao-Oger, M. Zhadobov, et al.. A Conformal Band-Notched Ultrawideband Antenna with Monopole-Like Radiation Characteristics. IEEE Antennas and Wireless Propagation Letters, 2020, 19 (1), pp.203-207. 10.1109/LAWP.2019.2958036 . hal-02472807

\section{HAL Id: hal-02472807 https://hal-univ-rennes1.archives-ouvertes.fr/hal-02472807}

Submitted on 12 Feb 2020

HAL is a multi-disciplinary open access archive for the deposit and dissemination of scientific research documents, whether they are published or not. The documents may come from teaching and research institutions in France or abroad, or from public or private research centers.
L'archive ouverte pluridisciplinaire HAL, est destinée au dépôt et à la diffusion de documents scientifiques de niveau recherche, publiés ou non, émanant des établissements d'enseignement et de recherche français ou étrangers, des laboratoires publics ou privés. 


\title{
A Conformal Band-Notched Ultrawideband Antenna with Monopole-like Radiation Characteristics
}

\author{
Bahare Mohamadzade, Student Member, IEEE, Roy B. V. B. Simorangkir, Member, IEEE, \\ Raheel M. Hashmi, Member, IEEE, Yann Chao-Oger, Maxim Zhadobov, Senior Member, IEEE, and \\ Ronan Sauleau, Fellow, IEEE
}

\begin{abstract}
A conformal, planar, and low profile ultrawideband (UWB) antenna with monopole-like radiation and band-notched characteristics is presented. A circular patch shorted to the ground is combined with two rectangular slots and two concentric rings, to achieve an ultra-wide bandwidth from 3.8 to $8.3 \mathrm{GHz}$ with a single rejection band from 5 to $6 \mathrm{GHz}$. The monopolelike radiation features, generated by combining $\mathbf{T} \mathbf{M}_{01}$ and $\mathbf{T} \mathbf{M}_{02}$ operating modes of a circular patch antenna, are maintained over the entire operating bandwidth. The antenna has only $0.046 \lambda_{o}$ height at $3.8 \mathrm{GHz}$ and is realized using polydimethylsiloxane (PDMS)-conductive fabric composite technology making it highly flexible and physically robust. This was validated through severe bending tests with various curvatures.
\end{abstract}

Index Terms-Band-notched antenna, conductive fabric, conformal antenna, flexible antenna, monopole-like radiation pattern, polydimethylsiloxane, ultrawideband (UWB).

\section{INTRODUCTION}

Low profile ultrawideband (UWB) antennas with monopolelike radiation characteristics have been a popular solution to ground sensor networks, Unmanned Aerial Vehicles (UAVs), and Wireless Body Area Networks (WBANs) to name a few [1]-[3]. In such applications, UWB antennas having wide omnidirectional coverage, vertical polarization for minimum path loss, and at the same time small physical size are of supreme importance. Being very high in profile, conventional quarterwavelength monopole antennas or vertically-polarized electric monopole antennas over a ground plane, are consequently not an ideal solution, despite their radiation characteristic and recent improvements in bandwidth [4], [5].

There has been a considerable advancement in ways of achieving UWB antennas with monopole-like radiation while maintaining the profile low. This includes the utilization of sophisticated structures incorporating ring patches, loops, and monocones with and without shorted top-hat loadings [1] [3], [6]-[9]. Monopole-like radiation characteristics over ultrawide bandwidth of more than $100 \%$ were successfully demonstrated, with reduced antenna height to even lower than $0.05 \lambda_{o}$

This work was supported in part by the International Macquarie University Research Excellence Scholarship (iMQRES).

B. Mohamadzade and R. M. Hashmi are with the School of Engineering, Macquarie University, Sydney, NSW 2109, Australia (email: bahare.mohamadzade@students.mq.edu.au)

R. B. V. B. Simorangkir is with the University of Rennes 1, CNRS, Institu d'Electronique et de Télécommunications of Rennes (IETR)-UMR 6164, F35000 Rennes, France and the School of Engineering, Macquarie University, Sydney, NSW 2109, Australia (e-mail: roy.simorangkir@ieee.org).

Y. Chao-Oger, M. Zhadobov, and R. Sauleau are with the University of Rennes 1, CNRS, Institut d'Electronique et de Télécommunications of Rennes (IETR)-UMR 6164, F-35000 Rennes, France (e-mail: maxim.zhadobov@univ-rennes1.fr).

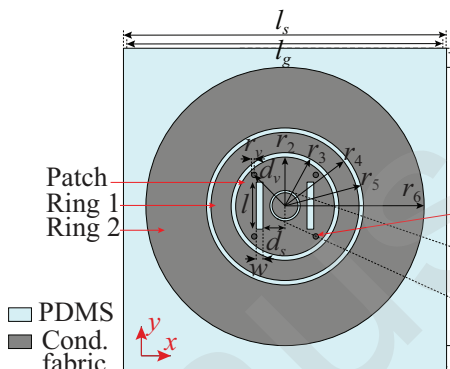

(a)

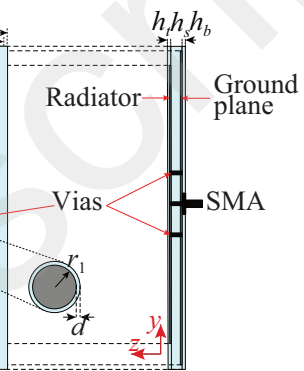

(b)
Fig. 1. Proposed antenna geometry: (a) front view, (b) side view. The final dimensions are $r_{1}=2.9, r_{2}=11, r_{3}=12, r_{4}=16.5, r_{5}=17.5, r_{6}=31$, $l_{s}=70, l_{g}=68, l=10.5, w=1.5, d_{s}=4.9, d_{v}=9.7, r_{v}=0.6, d=0.5$, $h_{t}=0.4, h_{s}=3$, and $h_{b}=0.2$. All dimensions are in millimeters.

at the antenna's lowest operating frequency. However, these successes generally come with some drawbacks. Among them are the need for auxiliary feeding or matching network, which remains a challenge for an antenna engineer, and the use of 3-D shaped structures and delicate parts (e.g., long and thin shorting or feeding strips/pins unsupported in the air). The latter particularly challenges the deployment of such antennas in modern wireless applications, which value antenna conformality and flexibility for better integration to system platforms with prescribed shapes, unobtrusiveness, users' comfort, and optimum use of limited spaces. In fact, all the aforementioned UWB antennas were composed of rigid materials.

Another important consideration for antennas that are used to sense ultra-wide bandwidth, is the strong interference from the existing wireless network technologies, for instance, IEEE 802.11a and HIPERLAN/2 in the $5.15-5.825 \mathrm{GHz}$ band. It is, therefore, a suitable approach to introduce a 'notch' in the bandwidth, to remove frequency bands susceptible to strong interference. The most common method to introduce the band-notched function to planar UWB antennas is by cutting slots with various shapes on the patch, ground plane, or feed line [10]-[12]. Other efforts by using electromagneticband gap (EBG) structures [13], [14], inclusion of vias [15], parasitic elements [16], [17], or combination of parasitic elements and slots [18], [19], have also been reported. Through these approaches, good band rejection performances have been achieved in a lot of UWB antenna designs, but rarely in the case of those having vertical monopole-like radiation characteristics.

In this paper, motivated by the needs described above, we propose for the first time a conformal and low profile 
UWB antenna with monopole-like radiation and band-notched characteristics. The antenna structure is based on a circular microstrip patch antenna, which does not require any matching circuit and completely planar with $0.046 \lambda_{o}$ height at its lowest operating frequency. By loading the patch with two rectangular slots, two parasitic rings, and vias, an ultra-wide bandwidth of 3.8-8.3 GHz with 5-6 GHz notched band has been achieved. The proposed antenna was fabricated based on the polydimethilsiloxane (PDMS)-conductive fabric composite technique, in which all antenna parts including radiators and ground plane are embedded inside the PDMS, making it flexible and resilient to the harsh environment [20]-[22]. The mentioned antenna characteristics along side its low profile and flexibility make the proposed antenna a suitable candidate for any applications with the need for wide coverage in all directions, particularly in which the antenna has to be placed on the non-flat surface, near to the ground.

\section{Antenna Configuration and Design Method}

The proposed antenna configuration is depicted in Fig. 1 and its optimized dimensions are given in the caption. The design comprises a proximity-fed circular patch loaded with two rectangular slots and the two ring patches. The main circular patch is connected to a full ground plane underneath, by four symmetrically placed vias. Both radiator and ground plane layers are placed on each side of a $3 \mathrm{~mm}$ thick PDMS substrate, having permittivity of 2.77 with an increasing loss tangent from 0.02 to 0.076 from 2 to $10 \mathrm{GHz}$ based on the measurement conducted using Agilent 85070E Dielectric Probe Kit. The antenna is coated completely with the same substrate material for mechanical robustness [20], which leads to a total antenna thickness of $3.6 \mathrm{~mm}$.

As the antenna conductive parts, highly conductive fabric, a nickel-copper coated ripstop from Less EMF Inc., is used. In simulations, the conductive parts of the antenna were modeled as a box with the fabric thickness as specified by the manufacturer, $0.08 \mathrm{~mm}$. The box was then assigned an effective conductivity of $5.4 \times 10^{4} \mathrm{~S} / \mathrm{m}$, which is an approximated effective conductivity of the composite material consisting of PDMS and the chosen conductive fabric, obtained from our previous study [20], [21]. This was done to get an accurate simulation, considering the percolation of PDMS into the pores of the conductive fabric during the integration of both materials.

\section{A. Design Steps}

The main design strategy is to combine $\mathrm{TM}_{0 n}$ resonance modes of a circular patch over a certain bandwidth except for the target notched band, 5-6 GHz. Such monopolar operating modes were chosen over other modes (e.g., $\mathrm{TM}_{21}, \mathrm{TM}_{31}$ ) for its better azimuthal omnidirectional pattern and gain [23], [24]. We found that two modes, $\mathrm{TM}_{01}$ and $\mathrm{TM}_{02}$, are enough to achieve the aim of this work. The antenna simulations and optimizations were conducted using CST Microwave Studio 2018. The optimizations were done by also taking into account the tolerance of the antenna manual fabrication.

The general flow of the antenna design process is illustrated by the input reflection coefficient $\left(\left|S_{11}\right|\right)$ results, which are provided in Fig. 2 and explained in five steps below.

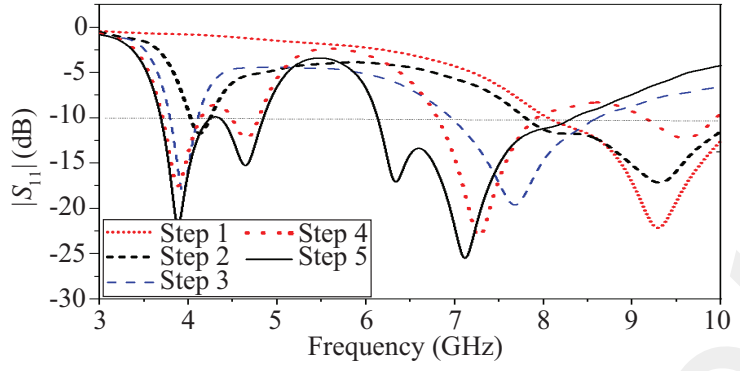

Fig. 2. Simulated $|S 11|$ of the antenna for each design step.

Step 1: Initially, a circular patch antenna was designed to operate in its $\mathrm{TM}_{02}$ mode at $9.3 \mathrm{GHz}$ [23]. The proximity feeding was chosen for more freedom in controlling the antenna bandwidth, for instance through the tuning of $r_{1}$ and $d$. However, the value of $d$ had to be maintained much smaller than the wavelength, to keep the operating modes of the patch.

Step 2: To add another resonance to the lower frequency region, we decided to generate a lower operating resonance mode $\mathrm{TM}_{01}$. To excite such mode which naturally does not exist in a pure circular patch antenna, shorting vias were introduced [23], [25], [26]. For maintaining a symmetrical current distribution on the patch, four vias were added to the patch in a symmetrical configuration. The optimum positioning of the vias resulted in the generation of $\mathrm{TM}_{01}$ resonance mode at around $4.1 \mathrm{GHz}$, while maintaining the resonance of $\mathrm{TM}_{02}$ mode at $9.3 \mathrm{GHz}$.

Step 3: Ring 1 was added at the perimeter of the patch. It was found that its coupling to the patch, controlled through the optimization of its radius and the gap to the patch, can lead to the resonance shift particularly in the $\mathrm{TM}_{02}$ operating mode, thus controlling the notched band achieved from Step 2. As can be noted in Fig. 2, the $\mathrm{TM}_{02}$ resonance shifted from 9.3 $\mathrm{GHz}$ to $7.7 \mathrm{GHz}$. A shift in $\mathrm{TM}_{01}$ can also be noticed, although relatively marginal.

Step 4: Following step 3, ring 2 was added at the perimeter of ring 1 , to improve further the bandwidth characteristic of the antenna without changing the current distribution. We found that the right coupling between ring 2 and ring 1, achieved through the optimization of the radius of both rings and the gap between them, can improve the bandwidth of the $\mathrm{TM}_{01}$ resonance mode and further shift the $\mathrm{TM}_{02}$ resonance mode. This leads to a better notched characteristic of the antenna.

Step 5: Lastly, to narrow further the notched band, another resonance at approximately $6.3 \mathrm{GHz}$ was introduced by cutting two rectangular slots having an approximate $\lambda_{g} / 2$ length at $6.3 \mathrm{GHz}$, from the circular patch. The position and dimensions of the slots were optimized in such a way that their impact on the operating modes were minimum.

The surface current distributions of the antenna at two different frequencies, 4.2 and $6.8 \mathrm{GHz}$, are simulated and shown in Figs. 3(a) and (b). It can be deduced from the current patterns that, the two operating modes at these two frequencies correspond respectively to the $\mathrm{TM}_{01}$ and $\mathrm{TM}_{02}$ modes. The currents vary along the radial direction but are independent of the azimuth angle $(\phi)$, hence the produced fields [23], [27]. Consequently, vertical-monopole like radiations are expected from this antenna. 


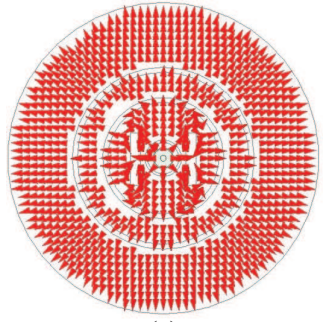

(a)

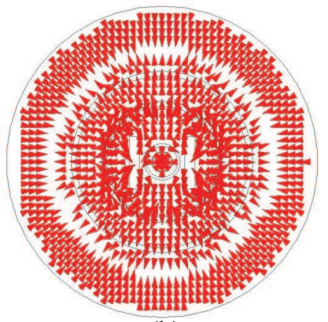

(b)
Fig. 3. Simulated current distributions on the patch surface at (a) $4.2 \mathrm{GHz}$ $\left(\mathrm{TM}_{01}\right)$ and (b) $6.8 \mathrm{GHz}\left(\mathrm{TM}_{02}\right)$.

TABLE I

PARAMETER VARIATIONS FOR NOTCHED-BAND TUNING

\begin{tabular}{c|l}
\hline Par. Set & Dimensions $(\mathrm{mm})$ \\
\hline \hline Set 1 & $r_{3}=12, r_{4}=16.5, r_{5}=17.5, r_{6}=31, l=10.5, w=1.5$ \\
Set 2 & $r_{3}=11.5, r_{4}=15, r_{5}=16, r_{6}=32, l=12, w=1$ \\
Set 3 & $r_{3}=13, r_{4}=18.5, r_{5}=19.5, r_{6}=31, l=9.5, w=1.5$ \\
Set 4 & $r_{3}=12, r_{4}=18, r_{5}=19.5, r_{6}=31.5, l=11.8, w=2.7$ \\
\hline
\end{tabular}

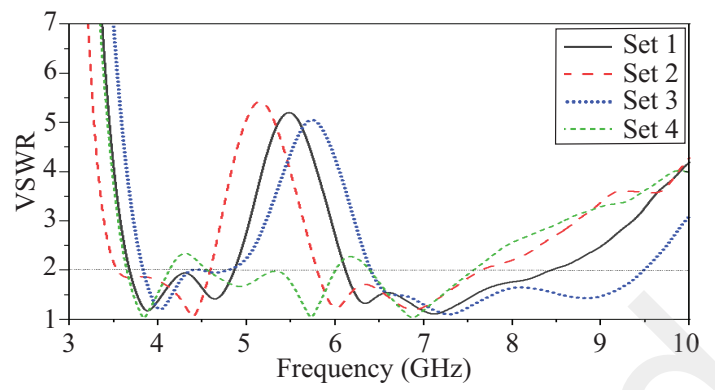

Fig. 4. Simulated VSWR of the antenna with different parameter sets.

\section{B. Antenna Parameters Effects on Notched Band}

From the design guideline described above, particularly steps 3 to 5 , it can be inferred some antenna parameters that have a significant effect on the notched band characteristic of the proposed antenna. Among them are $r_{3}, r_{4}, r_{5}, r_{6}$, $l$, and $w$. By simultaneously tuning these parameters, the rejection band of the antenna can be controlled. As examples, we conducted some simulations, where we varied these six parameters (Table I) and maintained the other parameters fixed as in the caption of Fig. 1. The simulated voltage standing wave ratio (VSWR) of each parameter set is given in Fig. 4, where we can see clearly the aforementioned role of these parameters. By properly arranging the resonance mode positions throughout the bandwidth, or equivalently having the right combination of these key parameters, the notched band can be tuned or even removed as demonstrated in the VSWR of set 4 in Fig. 4. As the changes were only made for the six parameters mentioned above, it can thus be implied from the results that, matching in the non-rejection bands can be improved through further optimizations of the overall antenna parameters. Also, it should be noted that a good monopole-like radiation performance was still achieved when the parameters variations given in Table I were applied.

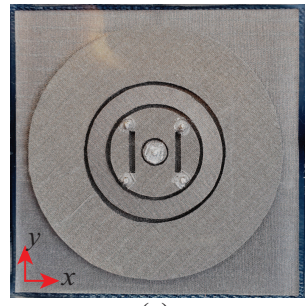

(a)

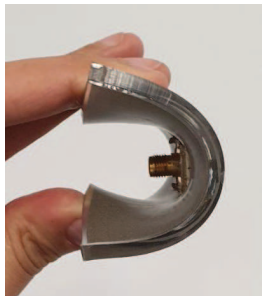

(b)
Fig. 5. Fabricated band-notched UWB antenna: (a) view from the top, (b) view while bent.

\section{PROTOTYPE FABRICATION}

A bottom-top assembly process as illustrated in [20], [21] was conducted to fabricate the antenna prototype. Each PDMS layer was prepared by pouring liquid PDMS into a customized ring-shaped mold having the required thickness, followed by curing in the oven. The conductive parts of the antenna were prepared by manually cutting the conductive fabric following the design in Fig. 1. The attachment of the conductive parts on the cured PDMS layers was done by using uncured PDMS. Upon completion of the layers assembly process, the vias were realized by using copper pins, pierced into the cured PDMS. Silver epoxy was used to connect the pins with the patch and the ground. Lastly, a SubMiniature version A (SMA) connector was connected from the bottom of the antenna with silver epoxy. The fabricated prototype is shown in Figs. 5(a) and (b).

\section{Results AND Discussion}

\section{A. Impedance Performance}

The VSWR of the fabricated prototype was measured using Agilent PNA-X N5242A network analyzer in both flat and bending conditions. The latter was done to verify its conformality and physical robustness against deformation. The measured result for the case of flat antenna is given in Fig. 6, alongside the numerically computed result from the simulator, showing a good agreement. As can be seen in Fig. 6, the measured VSWR is kept between 1 and 2 for the entire bandwidth of 3.8 to $8.3 \mathrm{GHz}$ except at the target notched band from 5 to $6 \mathrm{GHz}$. At the measured rejection band, the antenna has a peak VSWR of more than 4 at $5.5 \mathrm{GHz}$ with acceptable discrepancy compared to the simulated result. The differences between the measured and simulated results are most likely attributed to minute fabrication inaccuracies, for instance, during the manual cutting of the conductive fabric, the shorting pins inclusion, and the antenna patches assembly.

For the conformability testing, the antenna was bent along its $x$ - and $y$-axis over plastic tubes with various radii $\left(r_{b}\right)$, from 20 to $35 \mathrm{~mm}$, as illustrated in the inset of Fig. 7. The measured VSWR results of the antenna are given in Fig. 7, showing a stable performance of VSWR up to the bending radius of $30 \mathrm{~mm}$. The results under $x$-axis bending are also found to be very similar to those under $y$-axis bending. Repetitive bendings with smaller radius seemed to affect the connections between the conductive fabric and the SMA connector, realized by means of silver epoxy. Such occurrence is likely caused by the fact that the area around the connector where the silver epoxy was applied, turns to be more rigid than the other part 


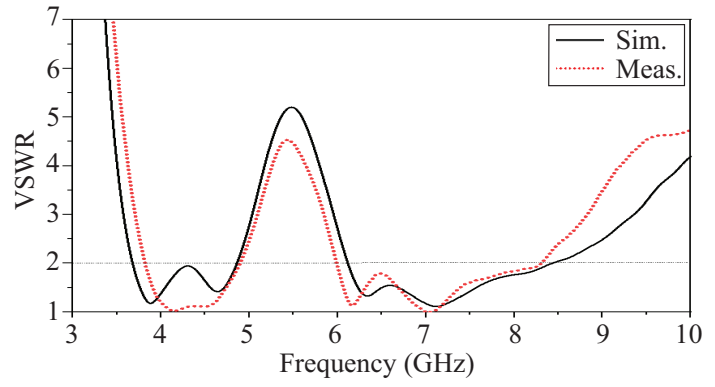

Fig. 6. Simulated and measured VSWR of the antenna in flat form.

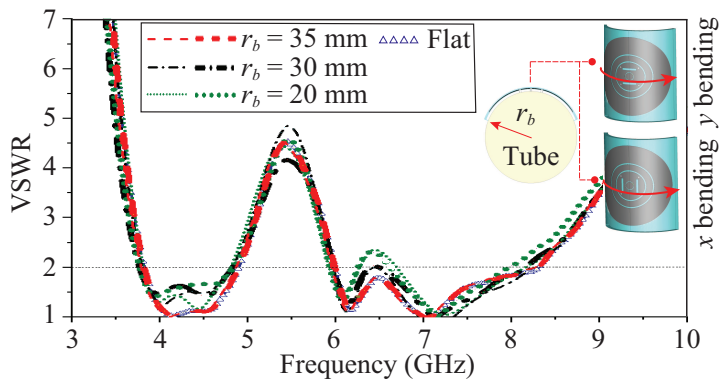

Fig. 7. Measured VSWR of the antenna under various $x$-axis (thin lines) and $y$-axis (thick lines) bending radii compared to that of the flat case (triangle symbol). The inset illustrates the bending test scenarios over plastic tube.

of the antenna. Moreover, the size of the SMA connector is comparable with the minimum bending curvature that possibly happens on that part of the antenna. The use of a smaller size connector or flexible conductive glue can, therefore, be implied to reduce this issue. Nevertheless, even after repetitive severe bendings, we noticed that the antenna can still return to its flat state without any cracks noticed on the PDMS layers or the conductive fabrics. This verifies its conformability and resilience against deformation.

\section{B. Far-Field Characteristics}

Figs. 8(a) and (b) show far-field patterns of the proposed antenna at two selected frequencies of 4.2 and $6.8 \mathrm{GHz}$ under flat and bending $\left(r_{b}=30 \mathrm{~mm}\right)$ scenarios, obtained from NSI700S50 spherical near-field anechoic chamber. A good agreement can be seen between the measured and simulated radiation patterns of the flat case. The results show that the antenna has a null in the broadside direction of $x z$ - and $y z$-planes with a good omnidirectional pattern in $x y$-plane, resembling the radiation features of a vertical monopole antenna. The physical deformation of the antenna indeed leads to slight deviations on its radiation patterns, for instance, the beam width and cross-polarization level. However, more importantly, the monopolar radiation mode is still maintained over the entire operating band of the antenna, even when the antenna is severely conformed.

The peak gains of the antenna are shown in Fig. 9. The measured results indicate that the proposed antenna when unbent, has a reasonably good gain over the operating bandwidth, ranging from 3 to $4.7 \mathrm{dBi}$ with an average of approximately $3.9 \mathrm{dBi}$ and a radiation efficiency of up to $60 \%$. On the other hand, a sharp decreased in the peak gain to a minimum level of $-9.7 \mathrm{dBi}$ can be noticed in the rejection band, validating
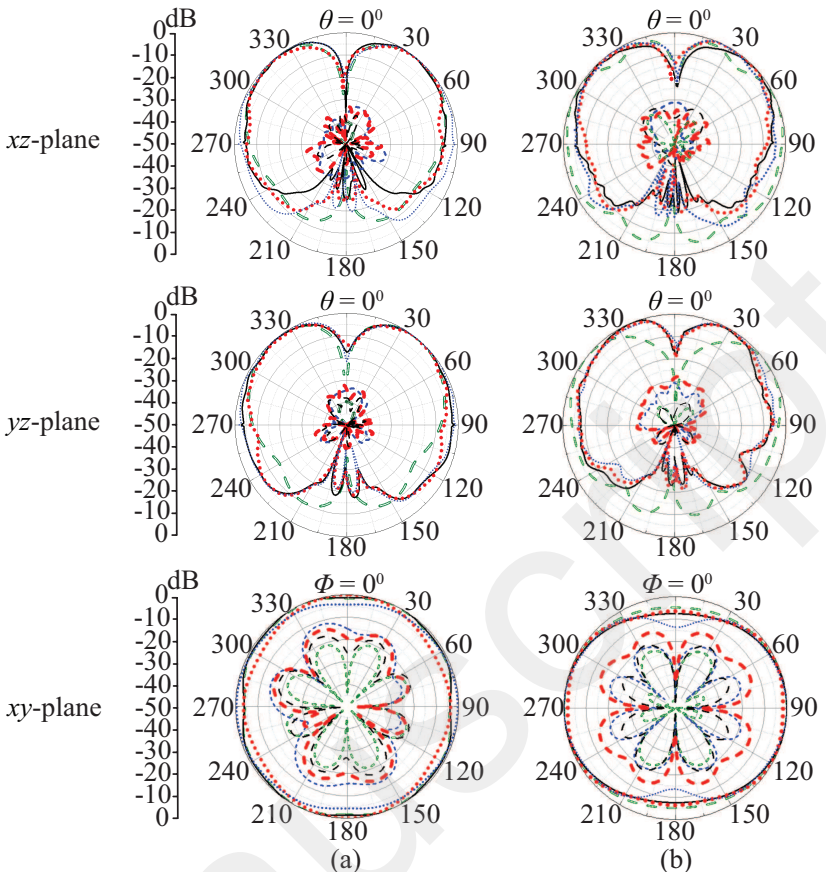

- - Sim. flat $\mathrm{E}_{\theta}$ —Meas. flat $\mathrm{E}_{\theta} \cdots$ Meas. $x$ bent $\mathrm{E}_{\theta} \ldots . . .$. Meas. $y$ bent $\mathrm{E}$

$\multimap$ Sim. flat $\mathrm{E}_{\phi}--$ Meas. flat $\mathrm{E}_{\phi}=-$ Meas. $x$ bent $\mathrm{E}_{\phi}=-$ Meas. $y$ bent $\mathrm{E}_{\phi}$

Fig. 8. Normalized simulated and measured radiation patterns of the proposed antenna in flat and bending $\left(r_{b}=30 \mathrm{~mm}\right)$ conditions at (a) $4.2 \mathrm{GHz}$ and (b) $6.8 \mathrm{GHz}$.

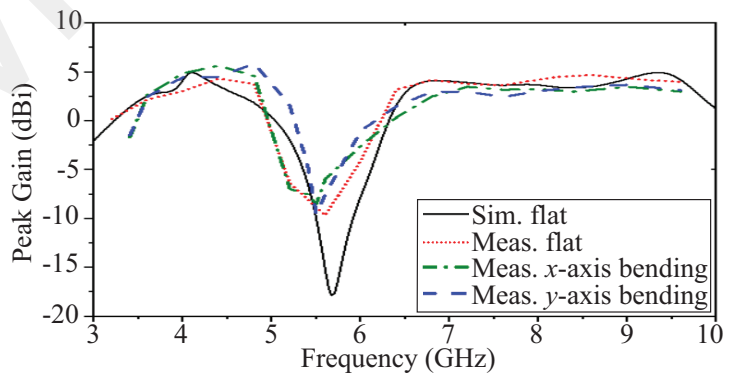

Fig. 9. Simulated and measured peak gains of the proposed antenna in flat and bending $\left(r_{b}=30 \mathrm{~mm}\right)$ conditions.

the optimum notched function of the proposed antenna. Such gain performance is seen to be relatively stable in both $x$ - and $y$-axis bending cases.

\section{CONClusion}

A new low profile band-notched UWB antenna has been presented. Different to previously reported band-notched UWB antennas, the proposed antenna has a vertical monopolelike radiation, which is maintained over the entire operating bandwidth. It also exhibits high flexibility and physical robustness as attributed to the employed PDMS-conductive fabric composite fabrication technology, which makes it suitable for conformal applications. This has been validated through a severe bending test over various radii. The measurements show that the unbent antenna covers 3.8 to $8.3 \mathrm{GHz}$ bandwidth with a notched band from 5 to $6 \mathrm{GHz}$. An average gain of $3.9 \mathrm{dBi}$ is shown across the operating bandwidth, which drops to up to $9.7 \mathrm{dBi}$ in the rejection band. This performance was reasonably maintained under different bending radii of up to $30 \mathrm{~mm}$. 


\section{REFERENCES}

[1] D. W. Aten and R. L. Haupt, "A wideband, low profile, shorted top hat monocone antenna," IEEE Trans. Antennas Propag., vol. 60, no. 10, pp. 4485-4491, 2012.

[2] J. Oh and K. Sarabandi, "Low profile vertically polarized omnidirectional wideband antenna with capacitively coupled parasitic elements," IEEE Trans. Antennas Propag., vol. 62, no. 2, pp. 977-982, 2014.

[3] D. Yang, J. Hu, and S. Liu, "A low profile UWB antenna for WBAN applications," IEEE Access, vol. 6, pp. 25 214-25 219, 2018.

[4] M. Ammann and Z. N. Chen, "Wideband monopole antennas for multiband wireless systems," IEEE Antennas Propag. Mag., vol. 45, no. 2, pp. 146-150, 2003.

[5] B. Mohamadzade and A. Rezaee, "Compact and broadband dual sleeve monopole antenna for GSM, WiMAX and WLAN application," Micro and Opt. Tech. Letters, vol. 59, no. 6, pp. 1271-1277, 2017.

[6] N. Nguyen-Trong, A. Piotrowski, T. Kaufmann, and C. Fumeaux, "Lowprofile wideband monopolar UHF antennas for integration onto vehicles and helmets," IEEE Trans. Antennas Propag., vol. 64, no. 6, pp. 2562 2568, June 2016.

[7] H. Zhang, F.-S. Zhang, and Y.-L. Yang, "An electrically small low-profile and ultra-wideband antenna with monopole-like radiation characteristics," Prog. In Electromagnetics Research Lett., vol. 70, pp. 99-106, 2017.

[8] N. Nguyen-Trong, S. P. Pinapati, D. Hall, A. Piotrowski, and C. Fumeaux, "Ultralow-profile and flush-mounted monopolar antennas integrated into a metallic cavity," IEEE Antennas Wireless Propag. Lett., vol. 17, no. 1, pp. 86-89, Jan 2018.

[9] A. A. Omar and Z. Shen, "A compact and wideband vertically polarized monopole antenna," IEEE Trans. Antennas Propag., vol. 67, no. 1, pp. 626-631, Jan 2019.

[10] R. Karimian, H. Oraizi, and S. Fakhte, "Design of a compact ultrawide-band monopole antenna with band rejection characteristics," IET Microw., Ant. and Propag., vol. 8, no. 8, pp. 604-610, June 2014.

[11] H. J. Mohammed, A. S. Abdullah, R. S. Ali, R. A. Abd-Alhameed, Y. I. Abdulraheem, and J. M. Noras, "Design of a uniplanar printed triple band-rejected ultra-wideband antenna using particle swarm optimisation and the firefly algorithm," IET Microw., Ant. and Propag., vol. 10, no. 1, pp. 31-37, 2016.

[12] Y.-Y. Liu and Z.-H. Tu, "Compact differential band-notched stepped-slot UWB-MIMO antenna with common-mode suppression," IEEE Antennas Wireless Propag. Lett., vol. 16, pp. 593-596, 2017.

[13] L. Peng and C.-L. Ruan, "UWB band-notched monopole antenna design using electromagnetic-bandgap structures," IEEE Trans. Microw. Theory Techn., vol. 59, no. 4, pp. 1074-1081, 2011.

[14] N. Jaglan, S. D. Gupta, B. K. Kanaujia, and S. Srivastava, "Band notched UWB circular monopole antenna with inductance enhanced modified mushroom EBG structures," Wireless Networks, vol. 24, no. 2, pp. 383393, 2018

[15] K. G. Thomas and M. Sreenivasan, "A simple ultrawideband planar rectangular printed antenna with band dispensation," IEEE Trans. Antennas Propag., vol. 58, no. 1, pp. 27-34, 2009.

[16] D. Yadav, M. P. Abegaonkar, S. K. Koul, V. Tiwari, and D. Bhatnagar, "A compact dual band-notched UWB circular monopole antenna with parasitic resonators," AEU-Int. Journal of Elect. and Comm., vol. 84, pp. 313-320, 2018.

[17] I. B. Vendik, A. Rusakov, K. Kanjanasit, J. Hong, and D. Filonov, "Ultrawideband (UWB) planar antenna with single-, dual-, and tripleband notched characteristic based on electric ring resonator," IEEE Antennas Wireless Propag. Lett., vol. 16, pp. 1597-1600, 2017.

[18] J. Zhang, P. Cao, Y. Huang, R. Alrawashdeh, and X. Zhu, "Compact planar ultra-wideband antenna with quintuple band-notched characteristics," IET Microw., Ant. and Propag., vol. 9, no. 3, pp. 206-216, 2014.

[19] A. A. Ibrahim, M. A. Abdalla, and A. Boutejdar, "A printed compact band-notched antenna using octagonal radiating patch and meander slot technique for UWB applications," Prog. In Electromagnetics Res. M, vol. 54, pp. 153-162, 2017.

[20] R. B. V. B. Simorangkir, Y. Yang, R. M. Hashmi, T. Björninen, K. P. Esselle, and L. Ukkonen, "Polydimethylsiloxane-embedded conductive fabric: Characterization and application for realization of robust passive and active flexible wearable antennas," IEEE Access, vol. 6, pp. 48102 $48112,2018$.

[21] R. B. V. B. Simorangkir, Y. Yang, and K. P. Esselle, "Robust implementation of flexible wearable antennas with PDMS-embedded conductive fabric," in Proc. 12 ${ }^{\text {th }}$ Eur. Conf. on Ant. and Propag. (EuCAP), April 2018, pp. 1-5.
[22] B. Mohamadzade, R. M. Hashmi, R. B. V. B. Simorangkir, R. Gharaei, S. Ur Rehman, and Q. H. Abbasi, "Recent advances in fabrication methods for flexible antennas in wearable devices: State of the art," Sensors, vol. 19, no. 10, p. 2312, 2019.

[23] R. Garg, R. Bhartia, I. Bahl, and A. Ittipiboon, "Circular disk and ring antennas," in Microstrip Antenna Design Handbook. Boston: Artech House, Inc., 2001, ch. 5, pp. 346-347.

[24] J. Tak and J. Choi, "Circular-ring patch antenna with higher order mode for on-body communications," Micro and Opt. Tech. Letters, vol. 56, no. 7, pp. 1543-1547, 2014.

[25] J. Liu, Q. Xue, H. Wong, H. W. Lai, and Y. Long, "Design and analysis of a low-profile and broadband microstrip monopolar patch antenna," IEEE Trans. Antennas Propag., vol. 61, no. 1, pp. 11-18, 2013.

[26] Y. Yang, R. B. V. B. Simorangkir, X. Zhu, K. Esselle, and Q. Xue, "A novel boresight and conical pattern reconfigurable antenna with the diversity of $360^{\circ}$ polarization scanning," IEEE Trans. Antennas Propag., vol. 65 , no. 11 , pp. 5747-5756, Nov 2017.

[27] B. Mohamadzade, R. B. V. B. Simorangkir, R. M. Hashmi, R. Gharaei, and A. Lalbakhsh, "Monopole-like and semi-directional reconfigurable pattern antenna for wireless body area network applications," Micro and Opt. Tech. Letters, vol. 61, no. 12, pp. 2760-2765, 2019. 